For Public Policy and Administration

\title{
What Happens on the Ground: Persistent Issues in Implementation Research
}

\author{
Peter Hupe \\ Department of Public Administration \\ Erasmus University Rotterdam
}

\begin{abstract}
Since the demise of what has been labelled as the policy-implementation paradigm, the heyday of implementation research appears to be over. This suggests that the issues going back to the 'top-down/bottom-up' controversy have been resolved. Central in this article is the exploration of how these issues are being dealt with in contemporary implementation studies. An issue like the one of the 'too many variables' seems to have been settled, especially in quantitative studies. Other issues, however, like the theory/practice relationship, the multi-layer problem and the policy/politics nexus appear to have remained relatively unsolved problems. Solutions are explored how to deal with them when doing implementation research.
\end{abstract}

Keywords policy implementation, implementation theory and research 


\section{What Happens on the Ground: Persistent Issues in Implementation Research}

\section{Introduction}

Whatever happened to implementation research? This question was explicitly raised by O’Toole (2000), DeLeon and DeLeon (2002) and Sætren (1996, 2005). Pressman and Wildavsky's publication of Implementation in 1973 marked the beginning of what would develop as the paradigmatic heyday of policy implementation research. By contrast, in the present 'age of governance' implementation research seems to have gone out-of-fashion. Its lost prominence may suggest a sort of quiet consensus has been established about how to research and write about public policy implementation. Having selected other objects of study present researchers of public policy and administration may take this assumption for granted; after all, we are supposed to talk about a 'yesterday's issue'. Also researchers currently interested in studying matters of implementation, like for instance those with a focus on 'multilevel governance', may have adopted this consensus - perhaps simply being not informed about the evolution of the scholarly field.

In this article that suggested consensus is treated as an empirical question. To what extent have the issues lying at the basis of the 'top-down/bottom-up' controversy indeed been resolved? If there are unresolved problems it seems worthwhile to identify those. The relevance of this subject matter can still be acknowledged. In the practice of public administration in most Western countries the days of extensive policy programmes, inherent to the growth of the welfare state, seem over. At the same time continuation can be observed. While new contractual arrangements for policy delivery have been developed, public policies are still being made daily. In areas like safety and security they are sometimes pursued with a rigour hardly seen before. In the study of public policy and administration, as well, continued attention is given to what happens 'after a bill has become a law' (Bardach, 1977). This attention, however, will not always be given under the heading of implementation research, or may be less prominently visible.

The identification of some important issues in implementation research and the manners in which contemporary implementation studies deal with them, is the objective of this article. By way of concluding the controversy raised in the 1970s and 1980s Goggin et al. (1990) pleaded for a 'synthesizing' approach, to be developed in 'third generation' implementation studies. Chronologically by now another 'generation' may have come up. The question is to what extent a 'synthesis' approach as pleaded for can be identified as having been adopted. It would mean that the original issues stemming from the top-down/bottom-up controversy would have been resolved. Because the quiet consensus is investigated rather than taken for granted, in a way, 'scholarly progress' is being measured. 
In order to investigate the central question, in the next section the characteristics of a 'synthesis' approach are defined, resulting in an exploration of an operationalization of four research issues. Next, contemporary research of policy implementation is being explored as pursued both within and beyond the policy-implementation paradigm, partly under different headings (third section). In the fourth section the focus is on how the authors of these contemporary approaches deal with the research issues articulated in section Two. When compared with each other, to what degree have present implementation studies adopted a 'synthesis' approach? In the fifth section the scope and substance of the identified issues are further explored and ways of resolving them are outlined and evaluated. The article ends with an answer to the question on the scholarly development of implementation research.

\section{Characterizing a 'Synthesis' Approach}

\section{A 'Yesterday's Issue'?}

As a broad term 'implementation' may refer to anything meant to happen after an intention or aspiration has been expressed. The theoretical core of what is called implementation theory and research as a scholarly field in the narrow sense, is usually addressed as a subdiscipline of Public Administration and Political Science. In this article the object of that field is defined as examining what happens within governmental agencies as well as in their relationships with other actors while fulfilling public tasks; and asking how that does matter (for alternative definitions see Pressman and Wildavsky, 1984: xxi; Ferman, 1990: 39; DeLeon, 1999: 314-15; Barrett, 2004: 251; O’Toole, 2000: 266 and 273, also 2005).

Implementation studies, in the indicated sense, have lost their fashionable character. In core journals on public administration, like Public Administration Review and the Journal of Public Administration Research and Theory, attention to the subject of implementation has considerably declined, as Moynihan (2008) has evidenced for the period 1998-2008. Implementation is ranked among the 'traditional' (p. 481) or 'classic' (p. 486) themes of public administration, like personnel management, red tape and political influence on bureaucracy. For the majority of academics the study of implementation has become a 'yesterday's issue' (for a critical analysis of that claim see Hill, 1997). Nevertheless the number of articles reporting on some kind of implementation research - often published in journals dedicated to specific poliy sectors - is still substantial, as Sætren (2005) has shown.

It is not immediately obvious how to measure the development of implementation research as a scholarly field. Particularly the operational question is how to formulate a 'yard stick' with which the present state of affairs can be assessed. As possibilities we see mapping a list of diagnostic observations drawn from existing reviews of the 
field; using a specific selection of issues made elsewhere (Hill and Hupe, 2014); or adopting an 'diagnosis-cum-agenda' as formulated in a report of a specific implementation study (Goggin et al., 1990).

\section{Measuring 'Progress' in Implementation Research}

Since Pressman and Wildavsky (1973) the development of the field has been reviewed by a range of scholars. Next to Sætren's bibliometric study already mentioned, other overviews are, in chronological order, Yin (1982), Alexander (1985), Sabatier (1986), O’Toole (1986, 2000, 2004, 2005), Lester et al. (1987), Linder and Peters (1987), McLaughlin (1987), Goggin et al. (1990), Ingram (1990), Palumbo and Calista (1990), Matland (1995), Ryan (1996), Hill (1997), Lester and Goggin (1998), DeLeon (1999), Winter (1999, 2006, 2012), Lester (2000), Sinclair (2001), Schofield (2001), DeLeon and DeLeon (2002), May (2003), Barrett (2004), Schofield and Sausman (2004), Pülzl and Treib (2006), Waters Robichau and Lynn (2009).

Several authors use straightforwardly dismissive qualifications when characterizing the state of the scholarly field: '(C)omplex, without much cumulation or convergence (..)’ (O’Toole, 1986: 181); '(y)et to reach conceptual clarity’ (Ingram, 1990: 462); 'misery research' (Rothstein, 1998: 62); 'an intellectual dead end' (DeLeon, 1999: 313); '(W)e know surprisingly little’ (Sætren, 2005: 559). Winter states (2006: 163): '(N)o general implementation theory has emerged. The implementation subdiscipline has been characterized by many different approaches representing different research strategies, evaluation standards, methodologies, concepts, and focal areas for research'. (..) 'The highly fragmented character of implementation research is not very conducive to theory accumulation’ (ibid.: 164, referring to Sætren 2005).

Some scholars, however, come to an assessment that is, at least, more mixed: 'There is more than meets the eye' (O'Toole, 2000: 265). He observes: 'One has to look, sometimes, in unusual places and be informed by a broader logic of intellectual development to make sense of the relevant scholarship. (..). (S)ome of the discourse has shifted, the questions have been broadened, and the agenda has become complicated' (ibid.: 263). Meier (1999: 6-7) comes to a similar conclusion. 'My biased survey of literature suggests that a wide range of journals publish articles that inform the study of policy implementation - the mainstream sociology journals, most of the public administration journals, the professions journals (public health, social work, sometimes law or medicine), many of the economics journals, and on rare occasion a political science journal. Much of this literature is not intended to directly answer questions of policy implementation, but it addresses concerns that are central to policy implementation.' Having found substantial numbers of articles in journals devoted to education, health, law, economics and the environment Sætren (2005: 562) concludes on the basis of an extensive bibliometric study of the field: '(T)he data 
overwhelmingly refute the decline proposition' (italics from the original). Pülzl and Treib (2006) arrive at a similarly mixed judgement on the state of the field.

These overviews provide rather overall assessments than explorations of specific theoretical and methodological issues. An alternative would be to use the selection made in the most recent state of the art. In the third edition of their monograph Hill and Hupe (2014, chapter 7) mention several issues researchers of implementation have to address: defining studies of implementation, explaining what needs explanation, isolating implementation as a part of the policy process, dealing with layers, specifying inter-organizational relationships, differentiating agency responses, identifying stakes, recognizing relevant macro factors, and making relevant decisions as far as quantitative and qualitative research designs are concerned. It is clear that when looking at how contemporary implementation research deal with these nine issues, a proper treatment of the whole range would go beyond the scope of this article.

A third option to measure the development of the field would be to adopt the diagnosis made by Goggin et al. (1990), before applying it in an analysis of the present state of knowledge. It seems justified to do so, as we will, because their book combines a review of the implementation literature up to that date with a report of empirical research. The book is particularly relevant because they also make concrete suggestions for 'third generation research', entailing 'conceptualizing, operationalizing, measuring and testing' (ibid.: 205). Hence Goggin et al. formulated a programmatic research agenda for implementation research, which can be used to assess how the field has developed more than two decades later.

\section{Four Questions}

By 'joining a quest for better theory with a search for improved practices' Goggin and his colleagues '(..) synthesize and assess two decades of theoretical and empirical research and chart the way for the next generation - a third generation - of research' (ibid.: iv). Aiming 'to make sense of the causal complexities of policy implementation' they argue for the adoption of a 'more "scientific" search for the patterned regularities as well as the idiosyncrasies of implementation decisions and actions' (ibid.: 8). They identify some 'major impediments' to the achievement of a satisfactory explanatory theory: 'too many variables, but too few cases, or "overdetermination"; a lack of attention to measures, and a missing orientation of 'empirical research that is truly comparative, longitudinal, and synthetic' (ibid.: 11). They elaborate these topics in subsequent paragraphs, headed as, respectively, the cases/variables problem, the lack of estimates, the neglect of the role of the states, and 'treating implementers as autonomous rational actors' (ibid.: 10-13). 
Goggin et al. observe that the nature of policy implementation invites case studies. At the same time it is difficult 'either to introduce the element of control for the effects of extraneous independent variables or to generalize from their findings' (ibid.: 10). They refer to Goggin's (1986) framing of this issue earlier as the 'too many cases/too many variables problem in implementation research'. The question here is then: Have solutions been found to deal with the variety of potential explanatory variables?

Second, instead of 'proverbs' (O’Toole 1986) and checklists, Goggin et al. identify a need for operational definitions of concepts and precise measures of variables are needed, as well as specified expectations about relationships among the various relationships, Goggin et al. state. One could add that a prescriptive (normative) orientation needs to be replaced by, or at least distinguished from, a descriptive (empirical) one: How do researchers address their relationship with the object of their research?

Third, Goggin and his colleagues observe that neither 'top-down' nor 'bottom-up' approaches to implementation research give sufficient attention to what they call the 'levels of analysis' issue. Therefore in the research project reported on in their book they use the United States as the primary unit of analysis. After all, the intergovernmental context of implementation influencing policy outputs includes federal- and local, as well as state-level variables. The question then is: How do researchers handle the fact that policy implementation, almost by definition, implies the involvement of multiple actors on different layers?

Fourth, Goggin et al. recommend the treatment of implementers as 'autonomous rational actors'. In fact, the political character of implementation is acknowledged in their work. Hence the question here is: How do researchers deal with the consequences of the complex, non-technical nature of policy making?

Goggin et al. (ibid.: 15) summarize their programmatic agenda for the field as follows: '(T)he challenge for the next generation of scholarship is to develop and test explanatory and predictive implementation theories of the middle range.' They add that this ambition implies - as 'the unique trait of third-generation research' - a research design characterized by an adequate treatment of the four issues mentioned above. Before addressing to what extent this is the case (in section Four), we first have to specify the present state of the study of implementation.

\section{Contemporary Approaches}

The Policy-Implementation Paradigm and Beyond 
Adapting Kuhn’s (1970) definition of a ‘paradigm’ Hill and Hupe (2014) historically locate the 'policy-implementation paradigm' as prevalent in the 1970s and closely connected to large-scale policy programmes of interventionist central governments. They identify the following characteristics of studies representing that paradigm. First there is the core assumption of implementation as a 'later' part in the policy process consisting of a range of 'stages'. After the particular public policy has been formulated and decided upon, its implementation follows subsequently. A second characteristic is the assumption that once one knows the objectives of a policy, one knows what to expect about its results. The official documents in which the policy has been laid down are seen as setting out these objectives. A final characteristic is the orientation 'at the top', in the geographical sense; it is at the ministries or other places in the centres of authority where policies are being made.

Hill and Hupe (2014) stress that also before the publication of Pressman and Wildavsky's classic there were implementation studies, although under different headings. In his bibliometric study Sætren (2005) underlines this observation. He particularly mentions the early evaluation studies in the mid-1960s of social reform programmes in the US as triggering the focus on policy implementation a decade later. In the same vein Sætren shows that substantial numbers of implementation studies are still reported on in journals on particular policy sectors, like education and health.

The sheer volume of studies that are, from one perspective or another, about implementation makes any effort to develop theory through bibliometric studies inapplicable. What can be done instead is to map the major streams of work in terms of categories. We do so below, distinguishing between 'mainstream', 'neo-' and 'advanced' implementation studies.

\section{Categories of Contemporary Implementation Research}

Mainstream implementation studies. Studies representing the policy-implementation paradigm most of the time will have a design of a single case-study, a usage of methods of qualitative research, and a 'downward' theoretical approach. The latter means that intentions and achievements are compared, while the policy goals as formulated are used as a starting point. Next the compliance with those goals is being documented, before assessing deviance from them.

On the agenda of the journals with a policy studies, public administration or public management focus, direct attention to implementation has been replaced in prominence by studies on subjects like performance, public sector reform and egovernment (Moynihan, 2008). Nevertheless the interest in what happens with Great Expectations in the daily practice of public administration remains, sometimes driven by more or less obvious 'policy failures'. It seems worthwhile to notice that also in 
much contemporary implementation research a straightforwardly prescriptive stance is adopted; see, for instance, Johansson (2010). Most of the time studies in this category involve a case-study of a single policy programme, offering a 'thick description' (Geertz, 1973), and adopting a 'view from the top'. Staying within the policy-implementation paradigm - in fact, still representing it - this category justifiably can be called mainstream implementation studies.

Neo-implementation studies. Under the heading of 'multi-level governance' since the 1990s various studies concerning policy making in the European Union have appeared (Peters and Pierre, 2001). The term multi-level governance is used to refer to policy making across more than one administrative layer, but with the addition of an extra layer, the one of the European Union. The fact that in most of such studies 'the top' in a particular policy process is not located in a national capital but in Brussels as the 'capital' of the EU, leads some researchers to address the activities of EU-member states, national governments, as 'implementation'. At the same time, at all 'levels' potentially a multiplicity of actors are active - inasmuch as EU-policy is likely to be in itself a product of multi-actor interaction. Among this multiplicity, nonstate actors like companies and organizations of interests, may become involved in the implementation process. Pertinent here is the debate within the EU literature between those who see 'implementation deficits' and those who focus on inter-governmental relations (cf. for instance Héritier and Lehmkuhl, 2008; Treib, 2008). The research design in studies of this kind often concerns a particular policy as a single-case, the methods used are mostly qualitative, while the theoretical approach is downward. Although under a different heading, that of 'multi-level governance', therefore actually the policy-implementation paradigm seems to prevail here. The combination of a contemporary locus looked at from a traditional focus makes Hill and Hupe (2014) speak of 'neo-implementation studies'.

Advanced implementation studies. As noted above, also nowadays implementation is researched in varying disciplines, such as management studies (cf. Hickson et al., 2003), and from different angles. Among those angles are decision-making (cf. Torenvlied, 2000), delegation (cf. Bendor et al., 2001), political control (cf. Meier and O’Toole, 2006), and (inter-) organizational conflict (cf. Oosterwaal and Torenvlied, 2009). In the SAGE Handbook of Public Administration edited by Peters and Pierre (2012) the section 'Implementation' has chapters expressing attention to the central subject from the focus of policy design, inter-organizational relations, and street-level bureaucracy. In his overview of the field Winter (2006) gives an exposition of 'third generation' implementation studies. What these studies have in common, and what makes them different from mainstream studies, is the elaborated character of their research design. When scientific rigour justifies calling these implementation studies advanced, a distinction can be made between studies in which a 'downward' or an 'upward' theoretical approach is being used. 
The studies mentioned in the beginning of this paragraph adopt a downward approach, as do ones on policy design and mandating (for instance, May 1993; 2006). Although implementation studies of this kind have a sophisticated research design, their rationale is a two-layer comparison. They start from policy intentions formulated at the top, while confronting them - 'downward looking' - with goal achievement at the bottom. On the other hand the studies of implementation looked at in terms of inter-organizational relations and street-level bureaucracy can be seen as embodying a different sub-category. They do have a research design going beyond a single casestudy (larger $n$ ), aiming at rigour also when qualitative research methods are used. These characteristics indicate therefore a research mode going beyond the policyimplementation paradigm, making them advanced. However, an 'upward' theoretical approach is employed (cf. Winter, 2006; UNICEF, 2012). This means the research objective is explaining empirical variation in respect of policy outputs or sometimes outcomes. Candidate explanatory factors are primarily sought at the micro- and mesolevel of analysis, on the basis of 'local' theory formation. Rather than making a twolayer comparison, upward studies start by looking at implementation variation, while treating policy intentions as among a range of independent variables.

Distinguishing between these categories of contemporary implementation studies, with the third divided in a downward and an upward variant, can be justified by the fact of the joint characteristics shared within each category. Of course there will be outliers, but the studies of each sort have a certain degree of similarity, particularly when the characteristics of the policy-implementation paradigm are used as a point of reference. We go on from this then, to address how these various categories of implementation studies deal with the issues of implementation research identified in Section Two.

\section{Comparing Approaches}

The four issues identified in section Two are important because of their enduring character. Therefore they were chosen as a way to measure the development of the scholarly field since the publication of Gogggin's et al. book. Apart from the problem of 'too many variables' the issues will be framed in terms of, respectively, the theory/practice relationship, the multi-layer problem (adopting Hill and Hupe's, 2003, wording) and the policy/politics nexus.

The problem of 'too many variables'. How do researchers deal with the variety of potential explanatory variables? Johansson (2010) recommends both implementers and implementation researchers interested in a specific policy to start with an indepth analysis of the nature of the policy and the nature of the implementation context' (ibid.: 122). To detect potentially problematic issues in the practice of the implementation of the policy Johansson recommends seeking answers from the clusters of independent variables identified by Hill and Hupe (2009) as potentially 
explaining implementation results. Since Johansson's object was to be helpful to policy makers these questions clearly imply a top-down perspective. This example is mentioned here because it shows the lasting relevance of the concern with goal achievement as characteristic of mainstream implementation studies. Rather than analytically redressing the number of potential causal variables, the selection of practically manageable factors is upfront here. Not so much seeking explanation of empirical variation but, in fact, establishing and possibly enhancing policy effectiveness is at stake. That the differences between implementation research and evaluation research hence may become confused, is a price easily paid.

Putting together two or three case comparisons, neo-implementation studies are essentially case studies. A conceptual framework consisting of (more than) a few key variables is applied in the analysis, hence consolidating rather than tackling the problem of 'too many variables'. In advanced implementation studies this problem is handled by a deliberate focus on specifying a limited number of hypotheses. They differ with their mainstream counterpart in having a quantitative research design, often with a large $n$, while formal modeling may be featuring. Also in qualitative studies the aim at scientific rigour implies a systematic conceptualization around a limited set of variables.

The theory/practice relationship. How do researchers address their relationship with the object of their research? Implementation research often, even currently, is characterized by an adoption of the goals of a public policy as legitimately decided upon and laid down in a formal document. As a consequence, the dependent variable in mainstream implementation studies tends to be goal achievement. Pressman and Wildavsky's (1973) subtitle of their classic book catches what since then paradigmatically has become known as an 'implementation gap'. If the observed implementation results in Oakland differ from the policy intentions as officially expressed in Washington, something on the way between them seems to have gone wrong. This type of approach has led to a lot of 'misery research' (Rothstein, 1998: 62).

Also in neo-implementation studies the adoption of the policy goals by the researcher may be joined by an identification with what has been articulated 'from the top'. When things go wrong - and it is clear they sometimes seriously do - the standard reaction implies a blaming of the implementers. Although in advanced implementation studies the stance of the researchers will remain an analytical one, the implication of studies in which a downward approach is pursued is similar. As the terms suggest, 'deviant' or 'non-compliant' behaviour is incorrect behaviour. However, Winter (2012) suggests a focus primarily on policy outputs, as the performance of implementers; thus recommending an upward approach. It is empirical variation in performance (horizontally) that needs explanation, rather than goal achievement (vertically). If there is variation in outputs within a sample of implementers (for example local governments) the explanation of that may lie in local 
activities, in ambiguity of the specification of objectives from the centre, or in other factors.

The multi-layer problem. How do researchers handle the fact that policy implementation, almost by definition, implies the involvement of multiple actors on different layers? Authors of mainstream implementation studies seem to deal with this fact each in their own way. Some authors acknowledge that policy goals may be deliberately not specified precisely, while extensive license is given to discretionary action. In the EU literature, for instance, a 'hard law'/'soft law' distinction is made and the term 'framework legislation' is used (cf. Knill and Lenschow, 2003; Treib, 2008). Implementation hence may be mandated in various ways. Multi-level governance studies and related literature particularly bring this out in the light of problems of enforcement and compliance by nation states, while encountering the 'problem of the many layers'. The proposition can equally be applied to issues within nation states about the mandating of implementation towards officials on lower layers (for example, Torenvlied and Akkerman, 2004). In the latter and similar advanced implementation studies the multi-layer problem usually is being addressed. Scholars like Torenvlied (a.o. 2000) analyze policy implementation by documenting the congruence between the results of what happens on two layers, that of political decision-making and the one of implementation. In studies with an upward approach the locus of investigation remains limited to one layer, usually the 'street-level'. Factors potentially explaining local variation may be sought in policy design, but not exclusively.

The policy/politics nexus. How do researchers deal with the consequences of the complex, non-technical nature of policy making? Within mainstream implementation formal policy documents are used as point of reference. The policy goals have been formulated and decided upon, while their implementation is expected to follow accordingly. Hence the measure stick is fixed; the goals have to be achieved as, more or less concretely, prescribed in the policy-on-paper. In neo-implementation studies the view is not fundamentally different. In fact, also in advanced implementation studies in which a downward approach is used congruence is being presupposed, as an implementation compliant with the stated policy goals (cf. Hupe, 2011). Actual action of implementers is looked at in corresponding terms, with 'divergence' or even 'deviation' as labels for what is seen as non-compliant behaviour.

In studies showing an upward approach, in contrast, the primary focus is on observed rather than presupposed behaviour. It is acknowledged that stated policies may be the result of social interaction between various actors, therefore may have an ambiguous character, and hence less function as a technical instruction. Important political intentions behind a policy often remain unwritten. While implementing public policies, street-level bureaucrats always have to act, often in unforeseen circumstances. Because there is an eye for these facts, in this kind of studies formal 
policy goals theoretically are treated as one input among a range of variables explaining actual policy performance.

\section{Issues Resolved?}

At the end of this section now the question can be answered, in what way the distinguished categories of implementation studies deal with the four problems Goggin and his colleagues deemed pertinent for the development of the scholarly field. To what extent have the four issues been resolved?

\section{PLEASE INSERT TABLE 1 ABOUT HERE}

As Table 1 shows, the answer is mixed. In advanced implementation studies explicit steps towards the formation of low- middle-range theories have been taken. Therefore the problem of 'too many variables' can be considered to have been resolved. This is to say, ways have been invented to deal with this issue - even if they are not equally being adopted in all categories of studies.

The theory/practice relationship concerns what Goggin et al. addressed in terms of a lack of a clinical view. Neo-implementation studies share with mainstream implementation an acceptance of policy goals. The latter are used as a standard implying formal 'intentions' actual 'achievements' are to be compared with. Advance implementation studies with an upward approach are the only ones in which an a priori or implicit adoption of policy goals is absent.

In mainstream implementation studies the 'problem of the many layers' is not really addressed. Rather more or less explicitly formal hierarchical relations are considered as prevailing. In fact, similar observations can be made about multi-level governance studies. Also in advanced implementation studies with a downward approach usually two layers are being looked at.

As far as the policy/politics nexus is concerned only in advanced implementation studies with an upward approach the possibility of legitimate action beyond formal mandates is being acknowledged and analyzed accordingly.

\section{Persistent Issues}

'What happens between the establishment of policy and its impact in the world of action'. That is what O'Toole (2000: 273) calls 'the core question of implementation'. Since Implementation (1973) the academic study of this question has proliferated. Four decades later as such though no longer in the centre of the international research 
agenda, implementation studies continue to be done - although not always as prominently visible as in the heyday of the policy-implementation paradigm.

In this article the focus has been on the ways contemporary implementation studies deal with four issues of implementation research. We identified these from the programmatic agenda for 'third-generation' implementation studies formulated in 1990 by Goggin and his colleagues. On the basis of our comparative findings in the previous section the question to what extent the four issues have been resolved, has been answered. As shown, the picture is mixed. Here, each of the issues will be reflected upon, from the perspective of ways how to deal with them in implementation research.

The problem of 'too many variables'. The problem concerns one of supposed causality. In the public domain numerous factors can be expected to influence the behaviour of actors, which are hard to isolate. Bowen (1982) investigated the implications of the chain metaphor used by Pressman and Wildavsky. Winter (2006: 157) observed that the research of the first and second generations of implementation studies 'had not succeeded in sorting out the relative importance of the explanatory variables. A substantial part of the studies could be criticized as merely presenting often long - checklists of variables that might affect implementation.' Speaking about 'forty-seven variables that completely explain five case studies' Meier (1999: 5) suggested: 'Any policy implementation scholar who adds a new variable or a new interaction should be required to eliminate two existing variables' (ibid.: 6). 'A literature with three hundred critical variables doesn't need more variables; it needs structure' (Matland, 1995: 146).

In their attempt to formulate a programmatic agenda for a 'third generation' of implementation studies Goggin et al. (1990) pleaded for a 'synthesis' approach. With its characteristics as outlined in section Two of this article it was meant to counter an ongoing promotion of isolated factors. Rigour and getting away from a predominantly normative orientation were important objectives. One of Goggin's co-authors later acknowledged that their level of aspiration was rather unrealistic (O’Toole, 2000: 272).

In dealing with the problem of 'too many variables' advanced implementation studies show that it is possible to formulate theoretical arguments in ways which allow them to be empirically tested. While qualitative studies can handle greater complexity, quantitative studies offer more scope for comparison and generalization. Since the latter are often data-driven it seems feasible to look beyond available data sets, seeking connections with other bodies of knowledge and research partners, across borders and across research communities.

The theory/practice relationship. The research problem involved here concerns the dilemma between seeking influence and accumulating knowledge. The problem 
regards the relationship between knowledge and action. As one of the most fundamental issues in social science it gets scholarly attention from various angles. In policy analysis a continuum of stances currently can be observed ranging from 'speaking truth to power' (Wildavsky, 1979) to 'making sense together' (Hoppe, 1999). It is commonly accepted that both mere instrumentality and overall societal irrelevance are to be avoided. This being so, in much implementation research almost by definition a 'top-down' view is being adopted, particularly when a case-study of a single public policy is involved. The assumption is then that once one knows the good intentions as laid down in a law or official policy document, one can infer the resultsto-be-realized from it. In other words: the policy inputs determine the policy outputs, in what is seen as a one-to-one relationship. However, premature judgements on 'implementation failures' and 'policy fiascos' may be the result. As far as this implicitly happens this may lead to confusing the normative and the empirical.

Winter's plea can be interpreted as one 'to start at the other end'. It can be adopted as a way to deal with the issue of the theory/practice relationship. Rigorous implementation research then begins with formulating a theory-based question, specifying what empirical variation in governmental outputs (and if possible outcomes) needs explanation, documenting what is known already and what not, and following a pragmatic research strategy. One could call this a bottom-up perspective that does not reject the case for systematic analysis.

The multi-layer problem. This research problem concerns dealing with complexity. Government acts at different geographical scales. These include that of the national ministries, local administration and even hospitals, but also, for instance, the European Union. Looking at neighbourhoods Somerville (2011: 82) defines multiscalarity as 'a property of trans-scalar action, or action across more than one geographical scale'. Earlier Goggin et al. (1990) argued for attention to the consequences of the 'multi-level' character of government appearances for implementation theory and research. In such 'multi-level' research there is a chance of confounding actors and activities, a phenomenon Hill and Hupe (2003) call the 'fallacy of the wrong layer'. The 'stage' of implementation is seen as a range of activities (focus) inherently connected with a certain category of actors working at a specific spot (locus).

'Opening up the black box' of street-level interaction may be advised as a way to deal with the multi-layer problem - with a reference to the subtitle of Palumbo and Calista 's edited book (1990). Looking at what happens and why in social interaction in micro-networks, however far from 'Washington', 'Whitehall' or 'Brussels', may imply a mode of analyzing implementation in a both scientifically advanced and societally highly relevant way.

The policy/politics nexus. This research problem concerns how to conceive policy analysis as social science analysis. Lowi (1972) has tried to distinguish between types 
of policy while looking at the substance of the latter. Many public policies - certainly in the area of human services, but not only there - have more than a technical character. Their substance may indeed be expected to matter. Implementing such policies means making value-loaded judgements.

In a study of Danish employment policy, for instance, May and Winter (2009: 466) point to (legitimate) differences between local and national officials in the way they address the same policy - differences related to its substance. Looking at the means and ends of a public policy as technical devices, and approaching their relations accordingly, may imply a pitfall. In fact it is seldom obvious when 'policy formation' ends and 'implementation' starts. Sometimes these two 'stages' in the policy process seem integrated, like in the management of the economy where a politically driven steering process is going on all the while.

In most cases there are institutional boundaries, which may obscure the possibility that actual 'policy formation' takes place where (only) 'implementation' is presumed. Observed behaviour of policy implementers then may be too readily judged as deviant from the norms laid down in the legal provisions of the policy. Policy goals but also policy instruments express a degree of conflict and consensus, and embody certain values. While May (2002: 226) speaks of 'policy politics' it can be stressed that all public policy is fundamentally political. Public policies have a political character, not in the least in the sense that questions are involved about 'what has to be implemented'.

Rather than hiding or ignoring political dimensions of public action, 'bringing politics back in' can be suggested to address the policy/politics nexus (cf. Evans et al., eds, 1985). This means the incorporation within research of attention to power mechanisms, stakes, values, symbolic aspects and other non-technical dimensions of public policies. All these elements, however 'political', can be treated in a clinical way by looking at 'what happens' rather than 'what should happen'.

\section{Conclusion}

A starting point for this article was searching to what extent a 'synthesis' approach can be identified as having been adopted in contemporary studies of implementation. Such an adoption might mean that the original issues stemming from the topdown/bottom-up controversy and identified in Goggin's et al. agenda for the scholarly field would have been resolved. In the previous sections the 'quiet consensus' referred to in the Introduction has been investigated. Now it can be concluded that, first, indeed 'scholarly progress' can be observed (cf. the two sub-categories of advanced implementation studies) while, second, simultaneously there is the chance of 'renaming the wheel' (cf. neo-implementation studies) next to, third, a sustained relevance of the top-down view (cf. mainstream implementation studies). 
It would be possible to suggest one single outlook of an 'ideal' research design (beyond single case-study), one preferable method (beyond 'no method'), and one theoretical approach (beyond description). However, the variety of sorts of implementation studies is a fact, and there is no reason to assume that any form of variety will disappear. Instead, one could ask what the identified categories of implementation studies could learn from each other. Given the findings of our comparison, authors of mainstream implementation studies, with a focus on policy outputs as goal achievement, could be advised to be aware of the thin demarcation line between analyzing goal achievement and evaluating policy effectiveness. To researchers doing implementation studies with a more advanced character but a similarly downward approach, in fact the same advice could be given. Researchers reporting on studies of multi-level governance could benefit perhaps from insights gained in the field of implementation theory and research. A next step for research with an upward character could be the further development of a comparative perspective, across policy domains and national boundaries.

Asking for a renaissance of implementation studies in 'the age of governance' seems useless. Research on public policy implementation may be out-of-fashion, but it is 'still very much alive and relevant' (Sætren, 2005: 559). Of the four identified issues of implementation research one appears to have been more or less resolved. Particularly implementation studies with a research design characterized by an $n$ larger than one, systematic usage of methods, and an explicit theoretical approach show structured ways of dealing with the problem of 'too many variables' by entering the path of theory formation. It is clear that this category of implementation studies, not without reason labeled 'advanced', scores relatively high on dealing with the other three issues as well - be it with some nuances. It is equally clear that what has been identified as the theory/practice relationship, the multi-layer problem, and the policy/politics nexus do not concern settled issues. In implementation research they remain needing attention - whatever the heading under which such research takes place.

\section{References}

Alexander E. R. (1985) From Idea to Action: Notes for a Contingency Theory of the Policy Implementation Process. Administration and Society 16(4): 403-426.

Bardach E. (1977) The Implementation Game: What Happens after a Bill Becomes a Law. Cambridge, Mass.: MIT Press. 
Barrett S. M. (2004) Implementation Studies: Time for a Revival? Personal Reflections on 20 Years of Implementation Studies. Public Administration 82(2): 249-262.

Bendor J., A. Glazer and Hammond T.H. (2001) Theories of Delegation. Annual Review of Political Science 4: 235-269.

Bowen E.R. (1982) The Pressman-Wildavsky Paradox. Journal of Public Policy 2(1): $1-21$.

DeLeon P. (1999) The Missing Link Revisited: Contemporary Implementation Research. Policy Studies Review 16(3/4): 311-338.

DeLeon P. and DeLeon L. (2002) What Ever Happened to Policy Implementation? An Alternative Approach. Journal of Public Administration Research and Theory 12( 4): 467-492.

Evans P.B., Rueschemeyer D and Skocpol Th. (eds) (1985) Bringing the State Back in. Cambridge: Cambridge University Press.

Ferman B. (1990) When Failure is Success: Implementation and Madisonian Government', in Palumbo D.J. and Calista D. (eds), Implementation and the Policy Process: Opening up the Black Box. New York: Greenwood Press, pp. 39-50.

Geertz C. (1973) The Interpretation of Cultures. New York: Basic Books.

Goggin, M. L. (1986) The 'Too Few Cases/Too Many Variables' Problem in Implementation Research. Political Research Quarterly 39: 328-347.

Goggin M. L., Bowman A.O’M., Lester J. P. and O’Toole Jr. L. J (1990) Implementation Theory and Practice: Toward a Third Generation. Glenview, Ill.: Scott Foresman/Little, Brown and Company.

Héritier A. and Lehmkuhl D. (2008) The Shadow of Hierarchy and New Modes of Governance. Journal of Public Policy 28(1): 1-17.

Hickson D.J., Miller S.J. and Wilson D.C. (2003) Planned or Prioritized? Two Options in Managing the Implementation of Strategic Decisions. Journal of Management Studies 40: 1803-1836.

Hill M. J. (1997) Implementation Theory: Yesterday's Issue? Policy and Politics 25(4): 375-385. 
Hill M. J. and Hupe P.L (2003) The Multi-Layer Problem in Implementation Research Public Management Review 5 (4) 471-490.

Hill M. J. and Hupe P.L (2014) Implementing Public Policy: An Introduction to the Study of Operational Governance, $3^{\text {rd }}$ edn. London: SAGE ( $2^{\text {nd }}$ edn.: 2009).

Hoppe R. (1999) Policy Analysis, Science and Politics: From 'Speaking Truth to Power’ to 'Making Sense Together'. Science and Public Policy 26 (3): 201-210.

Hupe P.L. (2011) The Thesis of Incongruent Implementation: Revisiting Pressman and Wildavsky. Public Policy and Administration 26 (1): 63-80.

Ingram H. (1990) Implementation: A Review and Suggested Framework, in Lynn N.B. and Wildavsky A. (eds), Public Administration: The State of the Art. Chatham, N.J..: Chatham House, pp. 462-480.

Johansson S. (2010) Implementing Evidence-Based Practices and Programmes in the Human Services: Lessons from Research in Public Administration. European Journal of Social Work 13(1): 109-125.

Knill Chr. and Lenschow A. (2003) Modes of Regulation in the Governance of the European Union: Towards a Comprehensive Evaluation. European Integration online Papers (EIoP), Vol. 7 No. 2003-001. Available at SSRN: http://ssrn.com/abstract=380680.

Kuhn T.S. (1970) The Structure of Scientific Revolutions, $2^{\text {nd }}$ edn. Chicago, Ill.: University of Chicago Press.

Lester J.P. (2000) Back to the Future in Implementation Research: A Response. Policy Currents 10(1-2): 2-5.

Lester J.P., Bowman A.O’M, Goggin M. L. and O’Toole Jr. L.J. (1987) Public Policy Implementation: Evolution of the Field and Agenda for Future Research. Policy Studies Review 7(1): 200-216.

Lester J.P. and Goggin M.L. (1998). Back to the Future: The Rediscovery of Implementation Studies. Policy Currents 8(3): 1-9.

Linder S.H. and Peters B.G. (1987) A Design Perspective on Policy Implementation: The Fallacies of Misplaced Prescription. Policy Studies Review 6(3): 459-475.

Lowi T.A. (1972) Four Systems of Policy, Politics and Choice. Public Administration Review 32: 298-310. 
Matland R. E. (1995) Synthesizing the Implementation literature: The AmbiguityConflict Model of Policy Implementation. Journal of Public Administration Research and Theory 5(2): 145-174.

May P.J. (1993). Mandate Design and Implementation: Enhancing Implementation Efforts and Shaping Regulatory Styles. Journal of Policy Analysis and Management 12: 634-666.

May P.J. (2006) Policy Design and Implementation, in. Peters B.G. and Pierre J. (eds), Handbook of Public Administration, $2^{\text {nd }}$ edn. London: Sage, pp. 279-291.

May P.J. and Winter S.C. (2009) Politicians, Managers, and Street-Level Bureaucrats: Influences on Policy Implementation. Journal of Public Administration Research and Theory 39(3): 453-476.

McLaughlin M.W. (1987) Learning from Experience: Lessons from Policy Implementation. Education Evaluation and Policy Analysis 9(2): 171-178.

Meier K.J. (1999) Are We Sure Lasswell Did it This Way? Lester, Goggin and Implementation Research. Policy Currents 9(1): 5-8.

Meier K.J. and O’Toole Jr. L.J. (2006). Political Control versus Bureaucratic Values: Reframing the Debate. Public Administration Review 66: 177-192.

Moynihan D.P. (2008). Public Management in North-America: 1998-2008. Public Management Review 10(4): 481-492.

Oosterwaal A. and Torenvlied R. (2009). Effects of (Inter-) Organizational Conflict: Public Policy Drift. Paper presented at the Annual Meeting of the Academy of Management, Chicago, Ill.

O’Toole Jr L.J. (1986) Policy Recommendations for Multi-Actor Implementation: An Assessment of the Field. Journal of Public Policy 6(2): 181-210.

O’Toole Jr. L.J. (2000) Research on Policy Implementation: Assessment and Prospects. Journal of Public Administration Research and Theory 10(2: 263-288.

O’Toole Jr L.J. (2004) The Theory-Practice Issue in Policy Implementation Research. Public Administration 82 (2): 309-329.

O'Toole Jr L.J. (2005) Implementation Theory and Research: Toward the Accumulation of Knowledge. Keynote speech, research seminar 'Implementation Theory and Research', Netherlands School of Government, Utrecht, October 28 (presented slides). 
Palumbo D.J. and Calista D. (eds) (1990) Implementation and the Policy Process: Opening up the Black box. New York: Greenwood Press.

Peters B.G. and Pierre J. (2001) Developments in Intergovernmental Relations: Towards Multi-Level Governance. Policy and Politics 29 (2) 131-135.

Peters B.G. and Pierre J. (eds) (2012) The SAGE Handbook of Public Administration, $2^{\text {nd }}$ edn. London: SAGE.

Pressman J. L. and Wildavsky, A. (1973) Implementation: How Great Expectations in Washington Are Dashed in Oakland (...), $3^{\text {rd }}$ edn. 1984. Berkeley, CA. and London: University of California Press.

Pülzl H. and Treib O. (2006) Policy Implementation, in Fischer F., Miller G.J. and Sidney M.S. (eds) Handbook of Public Policy Analysis: Theory, Politics and Methods. New York: Dekker, pp. 89-107.

Rothstein B. (1998) Just Institutions Matter: The Moral and Political Logic of the Universal Welfare State. Cambridge: Cambridge University Press.

Ryan N. (1996) Some Advantages of an Integrated Approach to Implementation Analysis. Public Administration 74: 737-753.

Sabatier P.A. (1986) Top-Down and Bottom-Up Approaches to Implementation Research: A Critical Analysis and Suggested Synthesis. Journal of Public Policy 6(1): 21-48.

Sætren H. (1996) Whatever Happened to Implementation Research? Paper for presentation at the conference of the Nordic Association of Political Science, Helsinki, Finland.

Sætren H. (2005) Facts and Myths About Research on Public Policy Implementation: Out-of-Fashion, Allegedly Dead, but Still Very Much Alive and Relevant. The Policy Studies Journal 33(4): 559-578.

Schofield J. (2001) Time for a Revival? Public Policy Implementation: A Review of the Literature and Agenda for Future Research. International Journal of Management Review 3(3): 245-263.

Schofield J. and Sausman C. (2004) Symposium on Implementing Public Policy: Learning from Theory and Practice: Introduction. Public Administration 82(2): 235248. 
Sinclair Th. A.P. (2001) Implementation Theory and Practice: Uncovering Policy and Administration Linkages in the 1990s International Journal of Public Administration 24(1): 77-94.

Somerville P. (2011) Multiscalarity and Neighbourhood Governance. Public Policy and Administration 26(1) 81-105.

Torenvlied R. (2000) Political Decisions and Agency Performance. Dordrecht: Kluwer Academic Publishers.

Torenvlied R. and Akkerman A. (2004) Theory of 'Soft' Policy Implementation in Multilevel Systems with an Application to Social Partnership in The Netherlands. Acta Politica 39(1): 31-58.

Treib O. (2008) Implementing and Complying with EU Governance Outputs. Living Reviews in European Governance 3(5): 4-30.

UNICEF Innocenti Research Centre (2012). Public Sector Reform for Children: Government Structures and Processes. Methodology and Guidelines for Case-Studies, Florence.

Waters Robichau R. and Lynn Jr. L.E. (2009) The Implementation of Public Policy: Still the Missing Link. Policy Studies Journal 37(1): 21-36.

Wildavsky A. (1979) Speaking Truth to Power: The Art and Craft of Policy Analyis. Boston, Mass.: Little, Brown and Company.

Winter, S.C. (1999) New Directions for Implementation Research. Policy Currents 8(4): 1-5.

Winter S.C. (2012) Implementation Perspectives: Status and Reconsideration, in Peters B. G and Pierre J. (eds) The SAGE Handbook of Public Administration, $2^{\text {nd }}$ edn. London: SAGE, pp. 265-278.

Winter S.C. (2006) Implementation, in Peters B. G. and Pierre J. (eds) The SAGE Handbook of Public Policy. London: SAGE, pp. 151-166.

Yin R.K. (1982) Studying the Implementation of Public Programs, in Williams W. and Elmore R.F. (eds), Studying Implementation: Methodological and Administrative Issues. Chatham, N.J.: Chatham House, pp. 33-72. 
Table 1. Modes of Dealing with Issues of Implementation Research

Category of studies Mainstream Neo AdvancedD AdvancedU

Issue

Too many variables

$+/-\quad+/$

Multi-layer problem

- + / + + +

Policy/politics nexus

$\begin{array}{llll}- & - & - & +\end{array}$

Theory/practice relationship -

$-\quad+/-$

$++$

$+$

(1iver 